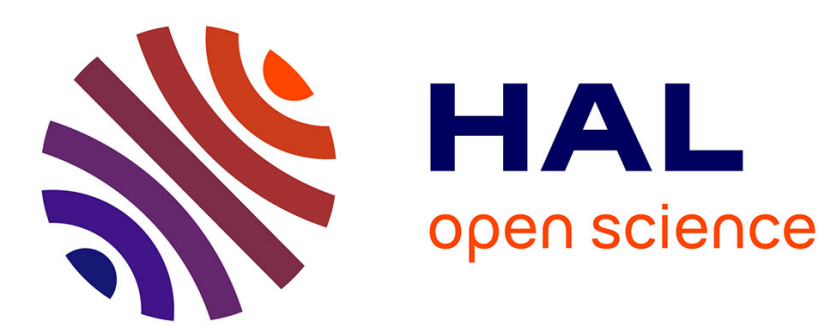

\title{
F-F' CONVERSION BY FLASH-LIGHT IRRADIATION OF ADDITIVELY COLORED KCl NEAR ROOM TEMPERATURE
}

\author{
M. Georgiev, T. Todorov
}

\section{- To cite this version:}

M. Georgiev, T. Todorov. F-F' CONVERSION BY FLASH-LIGHT IRRADIATION OF ADDITIVELY COLORED KCl NEAR ROOM TEMPERATURE. Journal de Physique Colloques, 1976, 37 (C7), pp.C7-89-C7-94. 10.1051/jphyscol:1976713 . jpa-00216853

HAL Id: jpa-00216853

https://hal.science/jpa-00216853

Submitted on 1 Jan 1976

HAL is a multi-disciplinary open access archive for the deposit and dissemination of scientific research documents, whether they are published or not. The documents may come from teaching and research institutions in France or abroad, or from public or private research centers.
L'archive ouverte pluridisciplinaire HAL, est destinée au dépôt et à la diffusion de documents scientifiques de niveau recherche, publiés ou non, émanant des établissements d'enseignement et de recherche français ou étrangers, des laboratoires publics ou privés. 


\title{
F-F' CONVERSION BY FLASH-LIGHT IRRADIATION OF ADDITIVELY COLORED KCI NEAR ROOM TEMPERATURE
}

\author{
M. GEORGIEV \\ Institute of Solid State Physics, Bulgarian Academy of Sciences, \\ Sofia 1113, Bulgaria \\ and

\section{T. TODOROV} \\ Central Laboratory of Optical Information Storage and Processing, \\ Bulgarian Academy of Sciences, Sofia 1113, Bulgaria
}

\begin{abstract}
Résumé. - La cinétique de la formation et de la décomposition des centres $\mathrm{F}^{\prime}$ produits par un éclair lumineux intense dans du $\mathbf{K C l}$ coloré additivement a été étudiée pour des intensités et des durées d'excitation lumineuse différentes dans l'intervalle de température 290-350 K. Nous avons trouvé des preuves de l'existence d'un processus de désexcitation à activation thermique qui tend à faire baisser l'efficacité d'ionisation du centre $F$ excité et à élargir la section efficace de piégeage de la lacune. Nous supposons que les probabilités de transition du centre $F$ excité et les sections efficaces de piégeage d'électrons dépendent de l'intensité, de sorte que l'on puisse rendre compte de la dépendance observée du taux de production à niveaux d'excitation élevés par rapport à la température et à I'intensité. Des résultats analogues ont été obtenus pour des centres $\mathrm{F}_{\mathrm{A}}(\mathrm{Na})$.

Abstract. - The yield and the decay kinetics of $F^{\prime}$ centers produced by an intense light flash in additively colored $\mathrm{KCl}$ are investigated at different excitation-light intensities and durations within the temperature range between $290-350 \mathrm{~K}$. Evidence is found for the occurrence of a thermallyactivated de-excitation process tending to decrease the ionization efficiency of the excited $F$ center and to increase the trapping cross-section of the vacancy. Both the transition probabilities of the excited $F$ center and the electron trapping cross-sections are assumed to be intensity-dependent to account for the observed temperature and intensity dependences of the yield at high excitation levels. Analogical results are obtained for the $\mathrm{F}_{\mathrm{A}}(\mathrm{Na})$ centers.
\end{abstract}

The primary objective of this work was an experimental investigation of the transient changes in the absorption spectra of colored alkali halide crystals which occur on illumination in the $F$ band near room temperature (RT). Under the experimental conditions employed the main changes resulted from the $F-F^{\prime}$ optical conversion. The present paper is aimed at summarizing all the collected data [1-7] and reconsidering their physical significance.

Experimental. - Inasmuch as the anticipated $\mathbf{F}^{\prime}$ lifetime was rather short - the order of $10^{-3} \mathrm{~s}[8]$, the most promising way to initiate and study the F-F' conversion at RT was by excitation spectroscopy, e. g. using a flash-light excitation.

The experimental technique has already been described in detail [2]. The flash-lamp, energized at about $40 \mathrm{~W} . \mathrm{s}$, was operated in two modes to produce light flashes of about $1 \mathrm{~ms}$ and $40 \mu \mathrm{s}$ effective durations respectively; for the sake of brevity these shall be referred to correspondingly as «Long Flash (LF)» and «Short Flash (SF)».
The samples were cleaved from large single crystals of $\mathrm{KCl}$ doped with about 0.1 mole $\% \mathrm{NaCl}$ and colored additively to the order of $10^{17} \mathrm{~F}$ centers $/ \mathrm{cm}^{3}$. The F-F' conversion was investigated in samples freshly quenched to RT following a 1-2 min thermal anneal at $400{ }^{\circ} \mathrm{C}$ to destroy aggregates and randomize the $F$ centers. Parallel studies were performed of the $F_{A}-F_{A}^{\prime}$ conversion after a preliminary $F_{A}$ center formation by optical bleach of the F band at RT.

Results. - That the transient absorption which occurred on flash-light excitation was due to $F^{\prime}\left(F_{A}^{\prime}\right)$ centers was verified in an investigation of the spectral distribution of $\Delta D$. A typical result obtained by a rapid-scanning equipment is shown in figure 1 representing both the bleach in the $F$ band range and the increase in absorption in the $F^{\prime}$ band range. The timekinetics of the transient absorption were investigated at various flash-light intensities and temperatures, both for SF and LF excitation. Inasmuch as the timeresolution of the photodetecting unit was inadequate for a proper study of the rise in absorption during the 


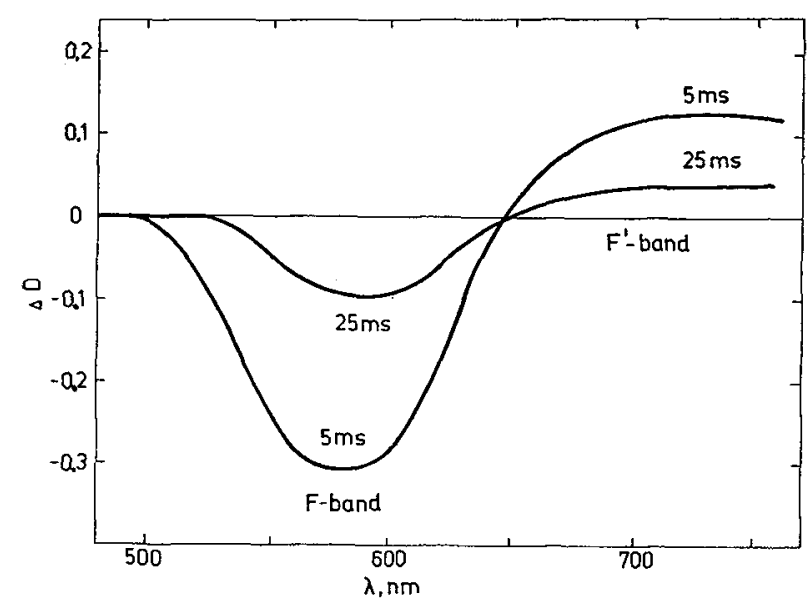

FIG. 1. - Spectrum of the optical density change induced by a light flash in a freshly-quenched sample, correspondingly at $5 \mathrm{~ms}$ and $25 \mathrm{~ms}$ after the excitation. The scan time was less than $60 \mu \mathrm{s}$.

light pulse, the only information about the processes under light was obtained from the yield $\Delta D_{\mathrm{m}}$ - the net change in optical density produced by the flash. At the same time the resolution was more than sufficient to secure a thorough analysis of the $F^{\prime}\left(F_{A}^{\prime}\right)$ decay in the dark.

Within reasonable limits of reliability the decay of $\Delta D$ in the dark was found to follow the equation $[3,4]$

$$
t=A(\Delta D)^{-1}+B \ln \Delta D+C
$$

where $A, B$ and $C$ are constants. This equation was exactly what was expected on the basis of the F-F' conversion model giving

$$
A \propto\left(\sigma_{\mathrm{F}} / \sigma_{\alpha}\right) \tau_{\mathrm{F}^{\prime}} \quad, B \propto\left(1-2 \sigma_{\mathrm{F}} / \sigma_{\alpha}\right) \tau_{\mathrm{F}^{\prime}} ;
$$

here $\tau_{\mathrm{F}^{\prime}}$ is the thermal lifetime of the $\mathrm{F}^{\prime}$ center, while $\sigma_{\mathrm{F}}$ and $\sigma_{\alpha}$ are the cross-sections for electron trapping at the $\mathrm{F}$ center and at the empty vacancy respectively.

The dependence of the yield $\Delta D_{\mathrm{m}}$ on the excitationlight intensity at RT was investigated for both SF and LF (Fig. 2) [2, 7]. The yield first increased with

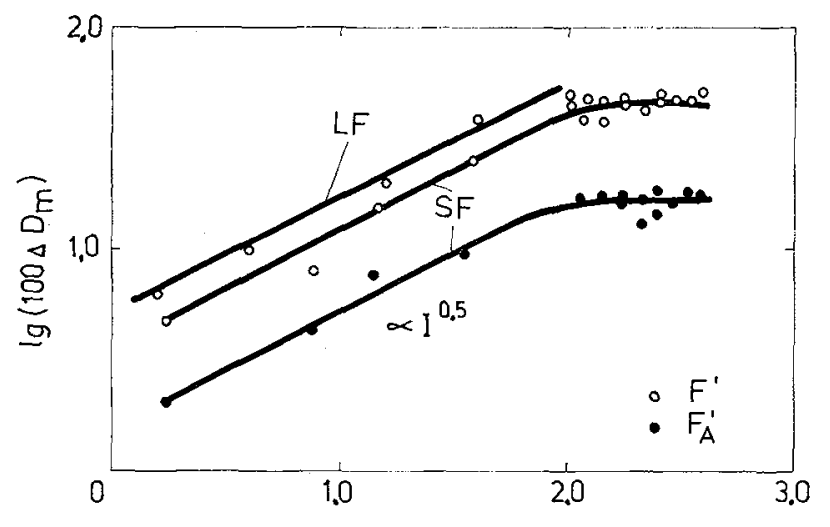

$\lg$ I, rel.u.

FIG. 2. - Dependence of the yield of the primed bands on the excitation-light intensity at room temperature for two flashlight durations : SF (10 $\mu \mathrm{s})$ and LF $(1 \mathrm{~ms})$. the intensity $I$ following the $I^{1 / 2}$ dependence but further gradually saturated. The corresponding dependences for the $F_{A}^{\prime}$ band exhibited the same general character. A more intriguing situation occurred with the temperature dependences shown in figures 3 and 4 where correspondingly the SF and LF yields both follow the Arrhenius functions but whith different activation energies $(0.41 \mathrm{eV}, 0.21 \mathrm{eV})$, which are $2: 1$ in ratio. Apparently the same situation appeared in the $F_{A}^{\prime}$ case but the activation energies were generally lower $(0.30 \mathrm{eV}, 0.15 \mathrm{eV})$.

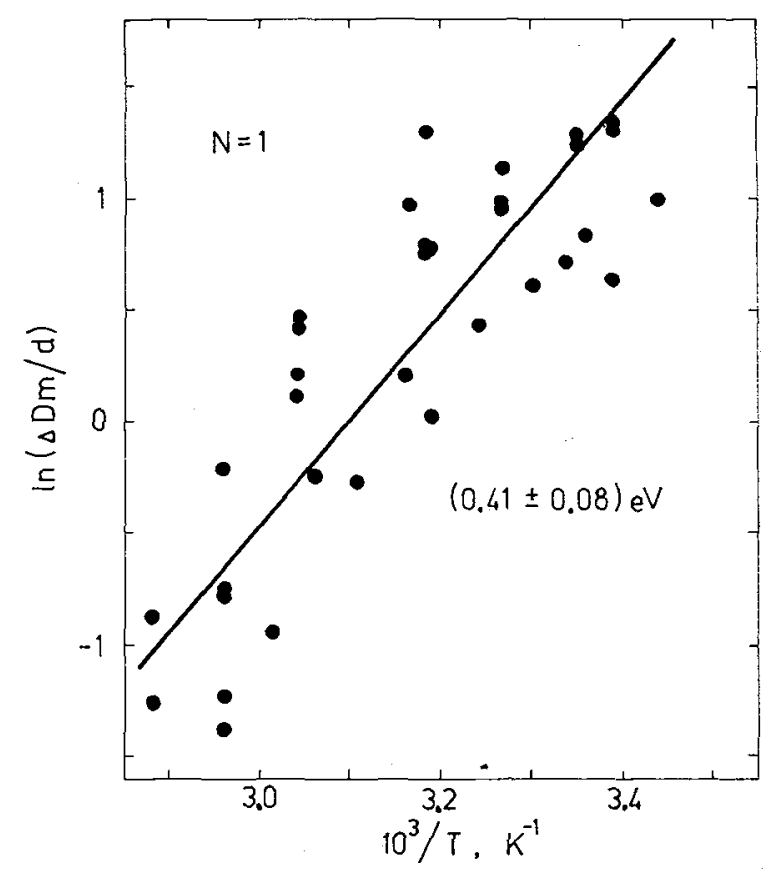

FIG. 3. - Temperature dependence of the SF yield for the $F^{\prime}$ band.

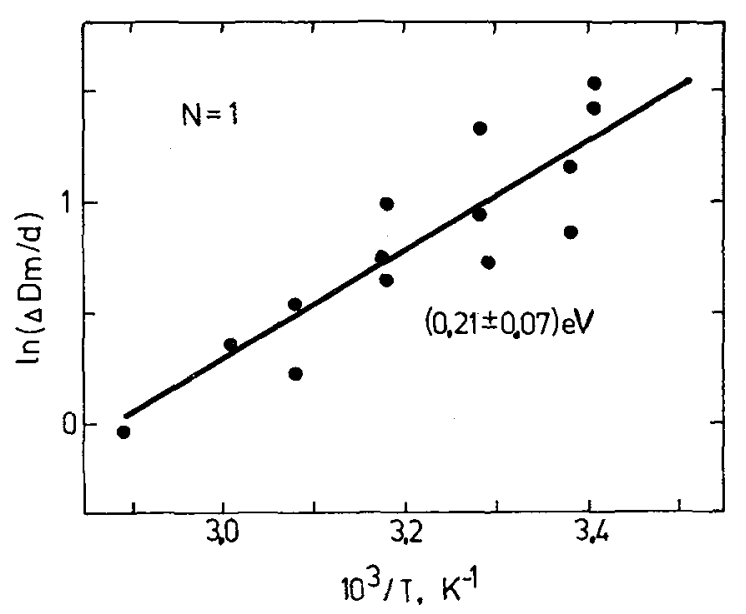

FIG. 4. - Same as figure 3 for the LF yield.

Perhaps not less intriguing are the temperature dependences of the decay kinetics. Figures 5 and 6 show the temperature behaviour of the bimolecular decay parameter $A$ which is Arrhenius for both $\mathrm{F}^{\prime}$ 


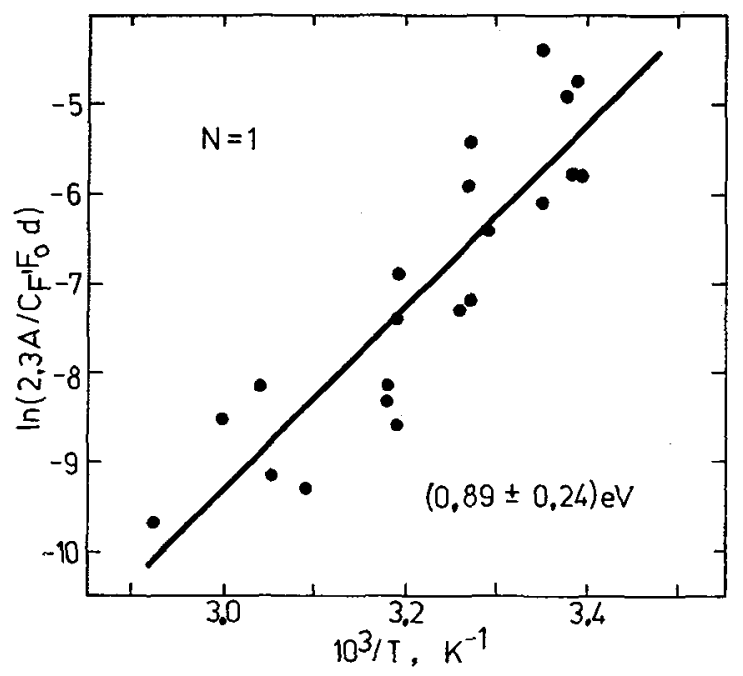

FIG. 5. - Temperature dependence of the bimolecular decay parameter $\boldsymbol{A}$ for the $F^{\prime}$ band. $F_{0}$ - the initial $F$ center density, $C_{F^{\prime}}$ - the $F^{\prime}$ absorption cross-section, $d$ - the sample thickness.

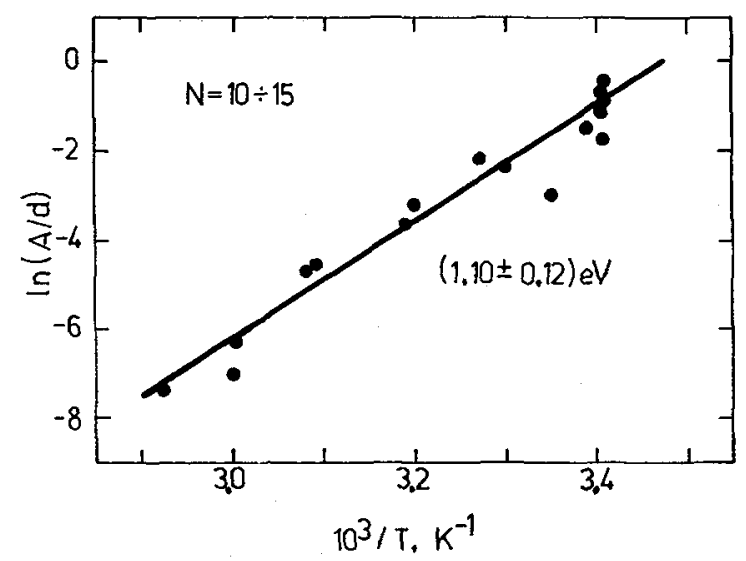

Fig. 6. - Same as figure 5 for the $F_{A}$ band.

and $F_{A}^{\prime}$ but with activation energies too high $(0.89 \mathrm{eV}$, $1.10 \mathrm{eV}$ ) to be ascribed to the corresponding thermal lifetimes alone. This suggests that $\sigma_{\mathrm{F}} / \sigma_{\alpha}$ might also be temperature dependent. Though the second parameter $B$ showed considerable scatter, an attempt was made to extract the values of $\sigma_{\mathrm{F}} / \sigma_{\alpha}$ and $\tau_{\mathrm{F}}$ from the data on $A$ and $B$. Obtained in this way both the thermal lifetime and the cross-sections' ratio were found to drop steadily as the temperature was raized.

Discussion. - The observed thermal ionization energy of the $F^{\prime}$ center $(0.42 \pm 0.21 \mathrm{eV})$, obtained from the $\tau_{\mathrm{F}}, v s$. reciprocal temperature plot, is, within the dispersion limits, not far from the values found by other authors [8-12] $\left(0.50 \mathrm{eV}\left(\mathrm{F}^{\prime}\right.\right.$ halflife) [8], $0.44 \mathrm{eV}$ (from an analysis of photoconductivity data) [9], $0.50 \mathrm{eV}$ (from the decay kinetics based on the assumption $\sigma_{\mathrm{F}} / \sigma_{\alpha}=0.5$ between $200-250 \mathrm{~K}$ ) [10], $0.53 \mathrm{eV}$ (from an analysis of the decay kinetics based on the assumption of a variable $\mathrm{F}^{\prime}$ lifetime) [11], $0.42 \mathrm{eV}$ (from an early analysis of photoconductivity data) [12].
The increased $F_{A}^{\prime}$ ionization energy $(0.75 \pm 0.05 \mathrm{eV})$ found presently seems consistent with the larger optical depth of the $F_{A}^{\prime}$ level below the conduction band. As mentioned above, the considerable dispersion in the present ionization energy data reflects mainly the scatter in the temperature data on $B$. A possible source of this scatter will be discussed later.

There are all reasons to believe that the observed temperature dependence of $\sigma_{\mathrm{F}} / \sigma_{\alpha}$ arises from $\sigma_{\alpha}$. Assuming excited-state pre-trapping $\left(\sigma_{\alpha}^{*}\right)$ in addition to direct ground-state trapping $\left(\sigma_{\alpha}^{\circ}\right)$ the cross-section $\sigma_{\alpha}$ for electron capture by the vacancy is given by

$$
\sigma_{\alpha}=\sigma_{\alpha}^{0}+\sigma_{\alpha}^{*} \tau_{\mathrm{F}} / \tau_{\mathrm{rF}}
$$

where $\tau_{\mathrm{F}}$ is the total lifetime, while $\tau_{r_{F}}$ is the total deexcitation time of the excited $F$ center $\left(F^{*}\right)$. The theory derives for the trapping coefficient (proportional to $\sigma_{\alpha}^{*}$ ) of a Coulomb center [13] $\gamma_{\alpha}^{*}=4 \pi e \mu / \varepsilon$ where $\mu$ is the electron mobility and $\varepsilon$ is the dielectric constant. The latter expression applies to both $\sigma_{\alpha}^{0}$ and $\sigma_{\alpha}^{*}$ indicating that these quantities are in effect nearly temperature-independent ; consequently the observed temperature dependence should arise from $\tau_{\mathrm{F}} / \tau_{\mathrm{x}_{\mathrm{F}}}$. Although the theory does not distinguish between $\sigma_{\alpha}^{*}$ and $\sigma_{\alpha}^{0}$ (provided both refer to a Coulomb center), it is intuitively clear that $\sigma_{\alpha}^{*}$ should exceed $\sigma_{\alpha}^{0}$, for the excited state in the field of the vacancy is much less compact and extends to a larger volume than the ground state. Moreover, the electronic potential in the ground state is not coulombic in character. Consequently, the trapping volume of the excited state may reasonably be expected to be much larger. For this reason we shall confine most of our discussion to trapping in the excited state neglecting the first term in the right-hand side of equation (2).

The total $\mathrm{F}^{*}$ lifetime $\tau_{\mathrm{F}}$ is given by

$$
\tau_{\mathrm{F}}^{-1}=\tau_{\mathrm{r}_{F}}^{-1}+\tau_{\mathrm{i}_{\mathrm{F}}}^{-1}
$$

where $\tau_{i_{F}}$ is the $F^{*}$ ionization time. Under normal conditions near RT thermal ionization can reasonably be expected to prevail over all other processes with the $\mathrm{F}^{*}$ electron ; consequently $\tau_{\mathrm{i}_{F}} \ll \tau_{\tau_{F}}, \tau_{F}=\tau_{\mathbf{i}_{F}}$ and

$$
\sigma_{\alpha}=\sigma_{\alpha}^{*} \tau_{i_{F}} / \tau_{\mathbf{r F}}
$$

Now, since the thermal ionization energy in $\tau_{i_{F}}$ is about $0.15 \mathrm{eV}$ for both $\mathrm{F}$ and $\mathrm{F}_{\mathrm{A}}$ it follows that an activation energy of the order of $0.5 \mathrm{eV}$ should be ascribed to $\tau_{\mathbf{r F}_{\mathbf{F}}}$. Thus the present data from the $F^{\prime}$ decay kinetics indicate that a thermally-activated de-excitation process occurs in both $F^{*}$ and $F_{A}^{*}$ near RT. It has been suggested earlier that at high vibrational quantum numbers the breathing mode oscillator in the $F$ excited state can pass non-radiatively into the $\mathrm{F}$ ground state with a probability proportional to $\exp \left(-E_{w_{F}} / k T\right)$ where $E_{w_{F}}$ is the height of the intersection point of the potential energy curves of the 
ground and excited states relative to the minimum of the excited state curve [14]. This process can be identified with the de-excitation observed presently. The obtained activation energy of about $0.5 \mathrm{eV}$, ascribed to $\tau_{\mathrm{r} F}$, is consistent with the height of the intersectionpoint barrier as calculated in the literature for the $\mathrm{KCl} F$-center on the basis of absorption and emission data [15].

Under certain assumptions the $F-F^{\prime}$ conversion model leads to the following equation for the development of the $F^{\prime}$ density with the time $t$ during a rectangular light pulse (cf. [9])

$$
\mathrm{F}^{\prime}(t)=\mathrm{F}_{\mathrm{S}}^{\prime} \tanh (t / \theta), \quad t \leqslant t_{\mathrm{flash}}
$$

where

$$
\mathrm{F}_{\mathrm{S}}^{\prime}=\mathrm{F}_{0} \sqrt{\left(\eta_{\mathrm{F}} \sigma_{\mathrm{F}} q_{\mathrm{F}} / \sigma_{\alpha} q_{\mathrm{F}^{\prime}}\right)}
$$

is the $F^{\prime}$ density at photoequilibrium, while

$$
\theta=\sqrt{\left(\sigma_{\mathrm{F}} / \sigma_{\alpha} \eta_{\mathrm{F}} q_{\mathrm{F}} q_{\mathrm{F}^{\prime}}\right)}
$$

is a time-constant which determines the time of attaining the photoequilibrium. Here $q_{F}, q_{F}$, are the optical excitation rates (per center) in the $F, F^{\prime}$ bands respectively. In accordance with the data on $\tau_{F^{\prime}}$ [4], the $F^{\prime}$ optical bleaching rate was assumed to exceed largely the $F^{\prime}$ thermal bleaching rate during the light flash $\left(q_{F^{\prime}} \gg \tau_{F^{\prime}}^{-1}\right)$. Since the exact shape of the growth kinetics is not known experimentally, we shall confine our discussion to the $F^{\prime}$ yield assuming that it is given by equation (4) at $t=t_{\text {flash }}$. This is justified at not too high excitation-light intensities when the yield is far from saturating with the intensity (the linear parts in Fig. 2). Assuming further that $t_{\mathrm{LF}} \gg \theta \gg t_{\mathrm{SF}}$ it follows

$$
\begin{array}{ll}
\Delta D_{m} \propto \mathrm{F}_{s}^{\prime}=\mathrm{F}_{0}\left(\eta_{\mathrm{F}} \sigma_{\mathrm{F}} q_{\mathrm{F}} / \sigma_{\alpha} q_{\mathrm{F}^{\prime}}\right)^{1 / 2}, & t_{\mathrm{f} 1}=t_{\mathrm{LF}} \\
\Delta D_{m} \propto \mathrm{F}_{0} \eta_{\mathrm{F}} q_{\mathrm{F}} t_{\mathrm{SF}}, & t_{\mathrm{f} 1}=t_{\mathrm{SF}} .
\end{array}
$$

The observed temperature dependences of the LF and SF yields whose activation energies are $1: 2$ in ratio suggest therefore that these originate from $\eta_{\mathrm{F}}$. However, as the decay kinetics indicate, $\sigma_{\alpha}$, which enters into $F_{s}^{\prime}$, is also temperature-dependent. Moreover in the approximation leading to equation (3) $\eta_{\mathrm{F}}=1$. In order to cope with this situation it will be assumed that non-linearities occur at high flash-light excitations leading to intensity-dependent $\tau$ 's, of the form

$$
\tau_{F}=\left\{\begin{array}{l}
\tau_{i_{F}}\left(\tau_{i_{F}} \ll \tau_{r_{F}}\right) \text { at low } I \\
\tau_{r_{F}}\left(\tau_{i_{F}} \gg \tau_{r_{F}}\right) \text { at high } I
\end{array}\right.
$$

The presumed non-linearity will obviously have a profound effect on the trapping cross-section $\sigma_{\alpha}$, given by equation (2), as well as on the ionization quantum yield

$$
\eta_{\mathbf{F}}=\tau_{\mathbf{F}} / \tau_{\mathbf{i F}_{\mathbf{F}}}
$$

At normal excitation-light intensities thermal ionization is predominant among all transitions of the $F^{*}$ electron $\left(\tau_{\mathbf{i}_{F}} \ll \tau_{\mathbf{r}_{F}}\right)$; consequently, $\sigma_{\alpha}$ and $\eta_{F}$ are given by equation (3) and $\eta_{F}=1$. At high excitationlight intensities the above situation is reversed : now the de-excitation process becomes predominant and as a result $\sigma_{\alpha}=\sigma_{\alpha}^{*}$, while

$$
\eta_{\mathrm{F}}=\tau_{\mathrm{xF}} / \tau_{\mathbf{i}_{\mathbf{F}}}
$$

As already revealed by the decay kinetics measurements, the thermally-activated transition is the main de-excitation process in the temperature range investigated. From these data and equation (10) it follows $\eta_{\mathrm{F}} \propto \exp (0.4 \mathrm{eV} / k T)$ for $\mathrm{F}$ and $\eta_{\mathrm{F}} \propto \exp (0.3 \mathrm{eV} / k T)$ for $\mathrm{F}_{\mathrm{A}}$. Having in mind that $\sigma_{\alpha}^{*}$ is practically temperature independent, this explains the observed temperature dependences of the SF and LF yields, proportional to $\eta_{F}$ and $\eta_{\mathrm{F}}^{1 / 2}$ respectively for both $F$ and $F_{A}$.

In any event, introducing the above non-linearity seems to be the most reasonable way to cope with the problem arising from the temperature behavior of the SF and LF yields [5]. Assuming a non-linearity would more or less mean a revision of the « conventional» F-F' conversion model with lifetime and trapping parameters constant in $I$. That this conventional model cannot explain the observed intensity dependence of the F-F' equilibrium at high excitation levels has been appreciated for some time [16]. Low temperature measurements have indicated that the $\mathrm{F}^{\prime}$ photoequilibrium density $\left(\mathrm{F}_{\mathrm{s}}^{\prime}\right)$ increases as $I$ is increased rather than remaining independent of the intensity as the model predicts. These deviations from the model have been interpreted in terms of an intensity dependence of $\sigma_{F}$ due to the presence of large amounts of ionized species. However, as the present measurements seem to show, non-linearities are likely to occur in the ionization efficiency as well.

The observed intensity dependences of the SF and LF yields are instructive in the pursuit of the origin of the non-linearities. Both yields have been found to be proportional to $I^{1 / 2}$ far from saturation which implies $\eta_{\mathrm{F}} \propto I^{-1 / 2}$ and $\sigma_{\mathrm{F}} / \sigma_{\alpha}^{*} \propto I^{3 / 2}$. Inasmuch as both yields have nearly the same intensity behavior and

$$
\Delta D_{\mathrm{m}_{\mathbf{S F}}} \propto \Delta D_{\mathrm{m}_{\mathbf{L F}}} / \theta
$$

$\theta$ is independent of $I$. An estimate of $\theta$ can be made based on $\sigma_{\mathrm{F}} / \sigma_{\alpha}^{*} \sim 0.05, \eta_{\mathrm{F}} \sim 1, q_{\mathrm{F}}=q_{\mathrm{F}^{\prime}} \sim 10^{3}$ leading to $\theta \sim 10^{-4}$ at $\mathrm{RT}$ which is quite reasonable.

The drop in ionization efficiency at high $I$ can be due to either a drop of $\tau_{r_{F}}$ or an increase of $\tau_{i_{F}}$. From the detailed ballance principle it follows

$$
\tau_{\hat{i}_{F}} \propto \sigma_{\alpha}^{*-1} \exp \left(E_{i_{F}} / k T\right)
$$

so that an increase of $\tau_{i_{F}}$ can be induced by a decrease of $\sigma_{\alpha}^{*}$ as $I$ is increased. That the cross-section of an anion vacancy can drop as a result of screening due to a near-by center has already been suggested [17]. An intensity dependence of $\sigma_{\alpha}^{*}$ would imply that the screening particle is either an excited or ionized neighbor. The alternative is to assume that while $\tau_{i_{F}}$ is constant $\tau_{r_{F}}$ is reversely proportional to $I^{1 / 2}$. This implies that the transition through the intersection- 
point barrier may be intensity-dependent through the effect of ionized and/or excited neighbors on the potential energy of the localized mode. The problem of an intensity-dependent $\sigma_{\mathrm{F}}$ seems more complex, though as before [16] the present experimental data require that $\sigma_{\mathrm{F}}$ should increase with $I$. The non-linearity in $\sigma_{\mathrm{F}}$ is likely to be related to some concentration effects on the $F^{\prime}$ lifetime below RT $[11,18]$. Since the $F^{\prime}$ density is intensity-dependent, they would imply a non-linearity occurring in $\tau_{F^{\prime}}$. This non-linearity can be understood in terms of the present result on $\sigma_{\mathrm{F}}$, since from the detailed ballance it follows

$$
\tau_{\mathrm{F}^{\prime}} \propto \sigma_{\mathrm{F}}^{-1} \exp \left(E_{\mathrm{F}^{\prime}} / k T\right) .
$$

Increasing the intensity would lead to increasing $\sigma_{\mathrm{F}}$ and, consequently, to decreasing $\tau_{F}$, in accordance with the experimental observation that $\tau_{F^{\prime}}$ is a declining function of the $F^{\prime}$ density [11].

The conclusion of an intensity-dependent $\sigma_{F}$ can throw some light on the origin of the scatter in the data on $B$ from the decay kinetics and on the greater stability of the bimolecular parameter $A$. As a matter of fact, while $B$ is more sensitive to variations in the flash-light intensity, the product $\sigma_{\mathrm{F}} \tau_{\mathrm{F}} / \sigma_{\alpha}$ is not since the main intensity-dependent quantity $\sigma_{\mathrm{F}}$ cancels.

The anticipated temperature dependences of $\sigma_{\mathrm{F}} / \sigma_{\alpha}$ and $\eta_{\mathrm{F}}$ for the $\mathrm{F}$ center as given by equations (2) and (9) respectively are illustrated in figure 7 . The solid lines represent experimental data, while extrapolations into regions where no such data are avalable are described by dashed lines. There are five temperature ranges determined by the relative magnitudes of the $\mathrm{F}^{*}$ electron transition probabilities, as well as by the $\sigma_{\alpha}^{*} / \sigma_{\alpha}^{0}$ ratio. At the lowest temperatures (range A) radiative de-excitation $\left(\tau_{\mathbf{R}_{\mathbf{F}}}^{-1}\right)$ predominates; consequently

$$
\eta_{F}=\tau_{\mathrm{R}_{\mathrm{F}}} / \tau_{\mathrm{i}_{\mathrm{F}}}, \quad \tau_{\alpha}=\sigma_{\alpha}^{*}+\sigma_{\alpha}^{0} \approx \sigma_{\alpha}^{*} .
$$

The data on $\sigma_{F} / \sigma_{\alpha}^{*}$ are an average of several measurements cited in the literature $[16,19]$. Within range $B$ the thermal ionization becomes more and more efficient so that now $\eta_{\mathrm{F}} \sim 1$ and $\sigma_{\alpha}=\sigma_{\alpha}^{0}+\sigma_{\alpha}^{*} \tau_{\mathrm{iF}_{\mathrm{F}}} / \tau_{\mathrm{R}_{\mathrm{F}}}$. Data in this range are available from experiments by Lüty et $a l$. [20]. However, $\sigma_{\mathrm{F}} / \sigma_{\alpha}$ will gradually saturate when as a result of the enhanced ionization probability trapping via the excited state becomes ineffective and is practically replaced by the direct trapping mechanism $\left(\sigma_{\alpha} \sim \sigma_{\alpha}^{0}\right.$, range C). Further, the thermallyactivated de-excitation is switched-on (range D); now, $\sigma_{F} / \sigma_{\alpha}$ drops steeply as a result of the new rise in trapping efficiency via the excited state due to the increased de-excitation probability. When the latter becomes predominant in range $\mathrm{E}$ the ionization quantum yield $\eta_{F}$ will also drop steeply. The non-linearities occurring at high excitation levels lead in effect to a shift of the temperature curves to lower temperatures. The conclusion that even at normal excitations the ionization quantum yield can be lower than 1 , provided the temperature is sufficiently high, is supported by more direct measurements of $\eta_{\mathrm{F}}$ at RT [21]. However this behaviour seems to be structure or impurity sensitive for the quantum yield has been found to vary considerably from sample to sample. This can be interpreted as a corresponding sensitivity of the trapping cross-section $\sigma_{\alpha}^{*}$, through the influence of other defects or impurities which disturb the otherwise purely coulombic character of the excited state pre-trapping. It is also likely that in samples of lower $\sigma_{\alpha}^{*}$ the transition temperature between ranges $\mathrm{D}$ and $\mathrm{E}$ would be lower. This possibly explains why the trapping coefficient $\gamma_{\alpha}$ of the anion vacancy has been found to be fairly temperature-independent virtually following the equation of a Coulomb center between 290-350 K [9], while our data point to a temperaturedependent $\sigma_{\alpha}$ within the same temperature range : The former results can well refer to range $\mathrm{E}$ in figure 7.

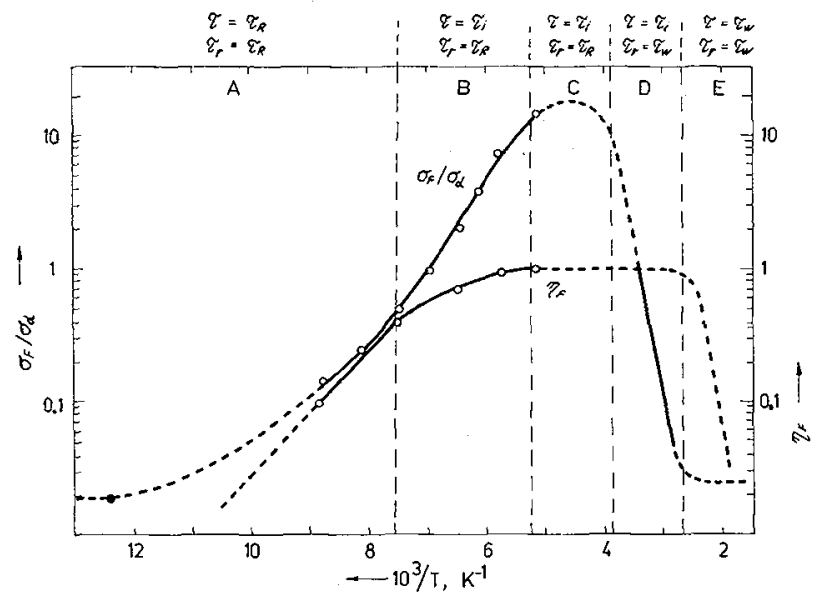

Fig. 7. - Presumed temperature dependences of the ionization quantum yield $\eta_{F}$ and the cross-sections' ratio $\sigma_{F} / \sigma_{\alpha}$. The available experimental data are plotted by circles, extrapolations are presented by dashed lines. The authors' data on $\sigma_{\mathrm{F}} / \sigma_{\alpha}$ are also included as a solid line with no circles. The whole temperature range is divided into five subranges, $A$ through $E$, according to the relative magnitudes of the transition probabilities of the excited $F$ electron as indicated on the top

Conclusion. - In the opinion of the authors an essential result of the present investigation is the revival of the problem of the non-linearities in the transition and trapping probabilities of color centers. While this problem is still far from being solved, the present study seems to have even added to its complexity by introducing new non-linearities. Clearly, a lot of experimental and theoretical work has to be done before these very intriguing properties are understood in detail.

Acknowledgment. - Thanks are due to Professor St. Petroff and the Physics Department at VIMMESS, Rousse for supplying the $\mathrm{KCl}$ crystals, as well as for numerous stimulating discussions. One of us (M. G.) is also indebted to the German Academic Exchange Service for a grant which made his participation at the Conference possible. 


\section{References}

[1] Dechev, G., Georgiev, G., Koralov, N., Todorov, T. Gochev, A., Georgiev, M., Proc. 5th IMEKO, Symp. Photon Detectors, Budapest 1971.

[2] Todorov, T., Dechev, G., Georgiev, M., Solid State Commun. 11 (1972) 1731.

[3] Toporov, T., Dechev, G., Tomova, N., Georgiev, M., Phys. Status Solidi (a) 15 (1973) K123.

[4] Todorov, T., Tomova, N., Georginv, M., Solid State Commun. 15 (1974) 1501.

[5] Georaiev, M., Todorov, T., Phys. Status Solidi (a) 27 (1975) K85.

[6] Todorov, T., Koralov, N., Georgiev, M., Opt. Commun. 13 (1975) 439.

[7] Todorov, T., Baltova, M., Grorgiev, M., C. R. Acad. Bulg. Sci. 28 (1975) 747.

[8] PICK, H., Ann. Phys. (5) 37 (1940) 421.

[9] Hoffmann, H. J., STöckmanN, F., Tödheide-Haupt, U., Phys. Status Solidi (b) 56 (1973) 549 ;

HoffmanN, H. J., Phys. Status Solidi 57 (1973) 123.
[10] Ikezawa, M., Hiral, M., Ueta, M., J. Phys. Soc. Japan $17(1962) 1474$.

[11] Goldberger, G. H., Thesis, Univ. of Connecticut, 1971.

[12] SeItz, F., Rev. Mod. Phys. 26 (1954) 7.

[13] Pekar, S. I., Issledovanija po elektronnoj teorii kristallov, Moscow 1951, p. 221.

[14] Pick, H., Nuovo Cimento 7 (1958) 498.

[15] Russell, G. A., Ktick, C. C., Phys. Rev. 101 (1956) 1473.

[16] Costrcas, A., Grossweiner, L. I., Phys. Rev. 126 (1962) 1410.

[17] Miehlich, A., Z. Phys. 176 (1963) 168.

[18] Schmid, D., Wolf, H. C., Z. Phys. 170 (1962) 455.

[19] Markham, J. J., F. Centers in Alkali Halides (Academic Press, New York) 1966.

[20] LüTY, F., Halbleiterprobleme 6 (1961) 238.

[21] Gudat, A. E., Scott, A. B., Wagner, M., J. Chem. Phys. 60 (1974) 4396. 